\title{
Endoscopic diagnosis of pyriform fossa lymphoma
}

\author{
A THOMSON FRACP, P MARLTON FRACP
}

\begin{abstract}
A Thomson, P MARlton. Endoscopic diagnosis of pyriform fossa lymphoma. Can J Gastroenterol 1996;10(7):447-448. Many endoscopists do not inspect the gastrointestinal tract superior to the cricopharyngeus, despite the fact that gastrointestinal symptoms (dysphagia, odynophagia and chest pain) can be produced by glottic and supraglottic lesions. A case of incoordinate swallowing secondary to a right-sided pyriform fossa lymphoma diagnosed at gastroscopy is presented.
\end{abstract}

Key Words: Endoscopic diagnosis, Gastroscopy, Pyriform fossa lymphoma

\section{Diagnostic endoscopique d'un lymphome du sinus piriforme}

RÉSUMÉ : Peu d'endoscopistes examinent la portion du tractus gastro-intestinal qui se trouve au-dessus du crico-pharynx, malgré le fait que les symptômes digestifs (dysphagie, odynophagie et douleur rétrosternales) peuvent être occasionnés par une atteinte glottique ou supraglottique. On présente ici un cas de déglutition incoordonnée secondaire à un lymphome du sinus piriforme droit découvert à la gastroscopie.
$\mathrm{M}$ any endoscopists do not inspect the gastrointestinal tract superior to the cricopharyngeus, despite the fact that gastrointestinal symptoms (dysphagia, odynophagia and chest pain) can be produced by glottic and supraglottic lesions. A case of incoordinate swallowing secondary to a right sided pyriform fossa lymphoma diagnosed at gastroscopy is presented.

\section{CASE PRESENTATION}

An 84-year-old man presented with a three-month history of progressive dysphagia and incoordinate swallowing. Food and liquid would "go down the wrong way", causing him to cough immediately after swallowing. He had a good appetite but had lost weight.

Past medical history was remarkable for chronic obstructive airways disease for which he took a theophylline derivative and intermittent courses of antibiotics. Seven years earlier he developed a cervical centrocytic non-Hodgkin's lymphoma that was treated with several courses of chemotherapy.
Examination revealed generalized wasting with bilateral jugulodigastric and submental lymphadenopathy. He also had small, palpable lymph nodes in both axillae and in the inguinal regions. Examination of the ninth to 12 th cranial nerves was normal, and the trachea was in the midline. His chest was clear to auscultation and abdominal examination was normal. There were no neurological signs to suggest motor neuron disease or Parkinson's disease. Four months previously, restaging confirmed stage 4 disease. Chest x-ray revealed features consistent with right hilar lymphadenopathy. A computed tomographic scan of the abdomen was not performed because there was existing clinical and radiological evidence of disseminated disease. A barium swallow performed before his referral demonstrated retention of barium within both valleculae and associated marked cricopharyngeal spasm. There was also incomplete filling of the left pyriform sinus and tertiary contractions of the lower esophagus. No intrinsic lesion within the esophagus was seen during the examination.

He was referred for gastroscopy. The day before endo- 
Figure 1) Gastroscopic view of larynx showing pyriform fossa mass

scopy, the hemoglobin was $13.8 \mathrm{~g} / \mathrm{dL}$, the white cell count, $4.5 \times 10^{9} / \mathrm{L}$ and the platelet count, $59 \times 10^{9} / \mathrm{L}$. At endoscopy, a 2 to $3 \mathrm{~cm}$ submucosal mass arising from the right pyriform fossa was demonstrated (Figure 1). The esophagus and stomach were normal. After consultation with the otolaryngology service, the pyriform fossa mass was biopsied during this gastroscopy. Aspirated blood was coughed after the procedure, but this settled following administration of ice.

Histology confirmed a centrocytic lymphoma consistent with dissemination from the previously diagnosed tumour, and prompt otolaryngological assessment was arranged. Radiotherapy was subsequently commenced and the patient's swallowing returned to normal over the next 10 days. The patient died four weeks later from complications of his lymphoma. An autopsy demonstrated widespread disseminated lymphoma, together with bilateral lower lobe bronchopneumonia, pulmonary hemorrhage and left ventricular fibrosis. The larynx and paralaryngeal structures were macroscopically normal.

\section{DISCUSSION}

Although about a quarter of patients with non-Hodgkin's lymphoma have extranodal disease at presentation, and the head and neck are common sights for such involvement (1), lymphoma of the larynx and paralaryngeal structures is rare (2). Most series of head and neck lymphomas have focused on patients whose disease was limited (or at least putatively limited) to the head and neck. In a series of 156 patients with non-Hodgkin's lymphoma of the head and neck where no such limitation was used (3), three cases involved the larynx. In a larger series of 1467 extranodal non-Hodgkin's lymphoma cases (1) in whom there was no evidence of disseminated disease at presentation, eight patients had lymphoma of the larynx and four of the hypopharynx. Siegel et al (4) described a case of cytomegalovirus laryngitis associated with probable lymphoma of the supraglottic region in a human immunodeficiency virus-positive patient presenting with odynophagia, hoarseness and weight loss. Donnelly et al (5) reported a 43-year-old male who died suddenly from airway occlusion secondary to an undiagnosed $4 \mathrm{~cm}$ non-Hodgkin's lymphoma arising from the right aryepiglottic fold. Importantly, extranodal lymphoma in areas threatening the airway often responds to radiotherapy and other treatment modalities (6).

\section{CONCLUSIONS}

The presented case demonstrates that gastroscopy can be useful in facilitating early diagnosis and prompt referral of patients with treatable and life-threatening lesions involving structures superior to the cricopharyngeus, and that such lesions can present with gastrointestinal symptoms rather than symptoms suggestive of laryngeal pathology. However, because the presented patient aspirated blood following endoscopic biopsy - and because performing such biopsies in this area is not standard practice among endoscopists - it is recommended that such lesions be referred to ear, nose and throat specialists for biopsy. Nonetheless it should be the practice of all endoscopists to inspect the vocal cords and paralaryngeal structures including the epiglottis; the wisdom of this approach is borne out by the presented case.

\section{REFERENCES}

1. Freeman C, Berg J, Cutler S. Occurrence and prognosis of extranodal lymphomas. Cancer 1972;29:252-60.

2. Shidnia H, Hornback N, Lingeman R, Barlow P. Extranodal lymphoma of the head and neck area. Am J Clin Oncol 1985;8:357-64.

3. Jacobs C, Hoppe R. Non-Hodgkin's lymphomas of head and neck and extranodal sites. Int J Radiat Oncol Biol Phys 1985;11:357-64.

4. Siegel R, Browning D, Schwartz D, Hudgins P. Cytomegaloviral laryngitis and probable malignant lymphoma of the larynx in a patient with acquired immunodeficiency syndrome. Arch Pathol Lab Med 1991;116:539-41.

5. Donnelly S, Hogan J, Bredin C. Sudden death from primary B-cell non-Hodgkin's lymphoma of the larynx. Respir Med 1991;85:77-9.

6. Hessan H, Houck J, Harvey H, Hershey P. Airway obstruction due to lymphoma of the larynx and trachea. Laryngoscope 1988;98:176-80. 


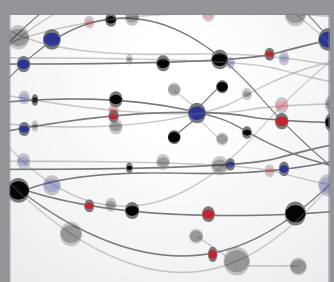

The Scientific World Journal
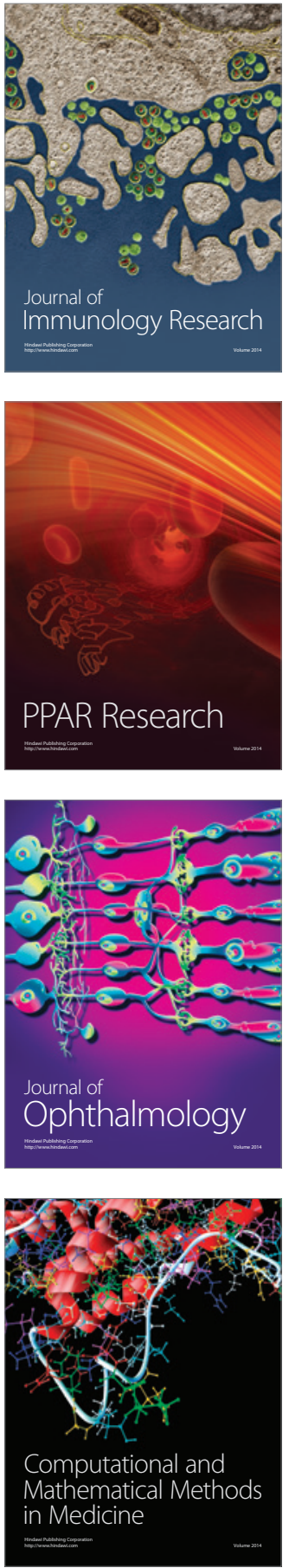

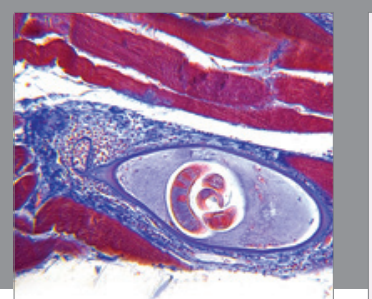

Gastroenterology Research and Practice

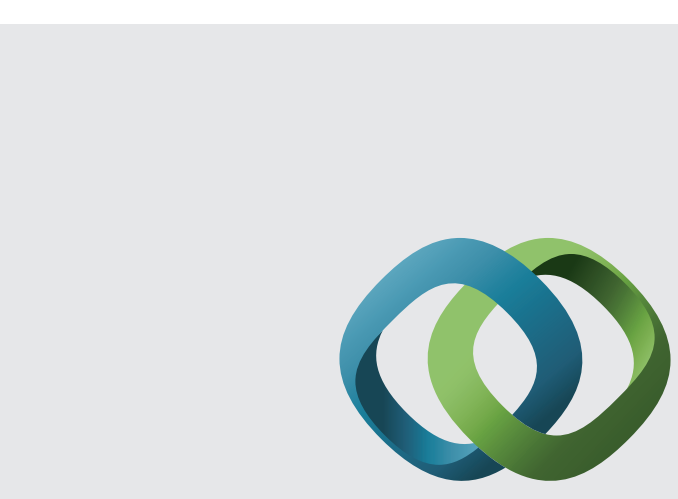

\section{Hindawi}

Submit your manuscripts at

http://www.hindawi.com
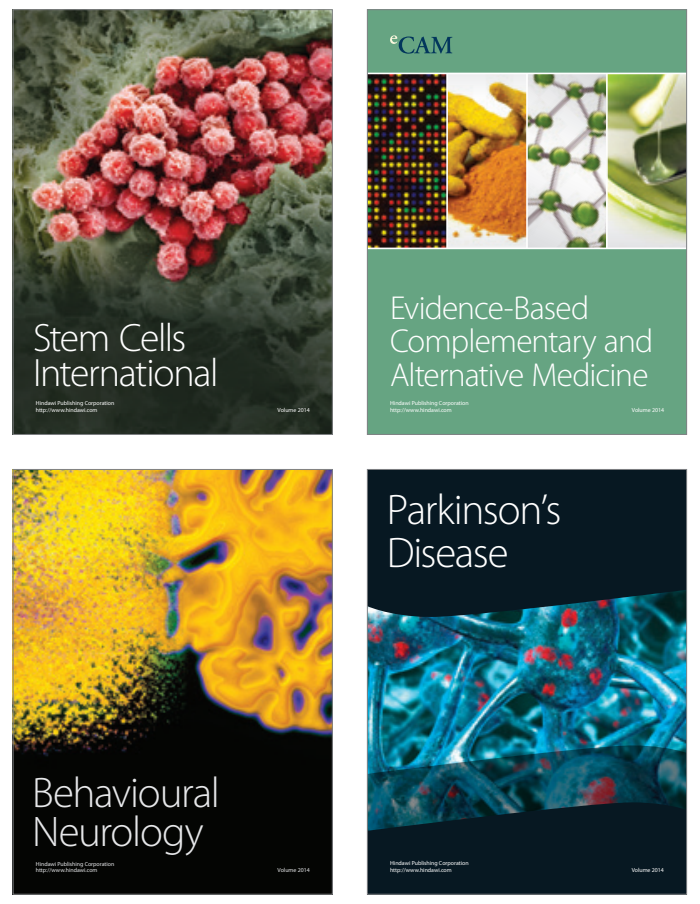
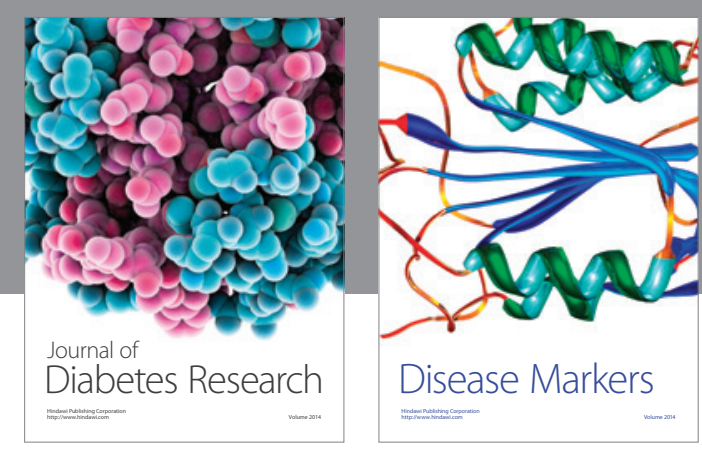

Disease Markers
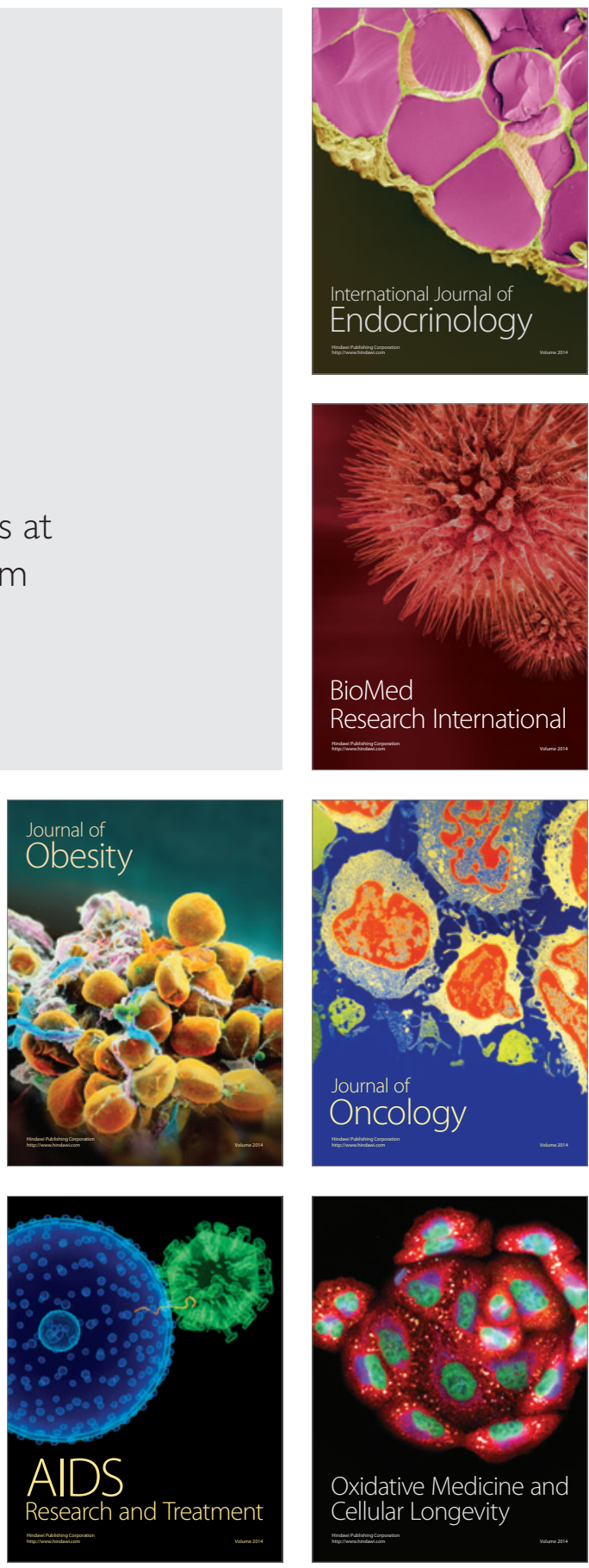